\title{
Relevance Theory and Its Application to Advertising Interpretation
}

\author{
Zhaohui Xu \\ Changchun University of Science and Technology, Changchun, China \\ Yanchun Zhou \\ Changchun University of Science and Technology, Changchun, China
}

\begin{abstract}
Relevance theory is a new way which attempts to show the nature of communication. Based on the classic code-model and Grice's inferential model, relevance theory holds "every act of ostensive communication communicates the presumption of its own optimal relevance." With the interpretation of advertising in the frame of relevance theory, this thesis shows advertising communication is ostensive-inferential.
\end{abstract}

Index Terms-relevance theory, ostensive-inferential communication, advertising

\section{INTRODUCTION}

Pragmatics is the study of the context-dependent aspects of utterance interpretation. It has developed rapidly during the last thirty years. Relevance theory given by Sperber and Wilson, shows the nature of communication and interprets pragmatics psychologically. The goal of pragmatics is to show how linguistic meaning interacts with contextual assumptions during utterance comprehension. To achieve this goal, we must not only deepen our theoretical understanding, but carry out detailed investigations of utterance interpretation in a wide variety of communication and contexts. Advertising is a unique form of communication, and interpretation of the advertisements within the frame of the relevance theory is an interesting practice.

\section{CODE MOdel AND GRicE’s INFERENTIAL MOdel}

The widely popular "code model" proposed by Shannon and Weaver (1962) represented a semiotic approach to communication. According to this model, communication involves the processes of encoding and decoding, and understanding is a matter of unintelligent, mechanical decoding. Yet Paul Grice (1975) provided an inferential view showing that communication is at least partly an intelligent activity. For him, to get the listener to recognize his intention is the only task a communicator has. Usually intentions are not decoded but inferred. The main purpose of pragmatics is to interpret how these intended implications are inferred. Grice saw inferential comprehension as governed by the Cooperative Principle and its maxims. The maxim-violation obviously would provide great help in the comprehension and the comprehension is a conscious and reasoning process based on contexts.

Both code model and inferential model have their weak points. Though most human communication involves the process of encoding and decoding of linguistic symbols, yet complicated, esp. context-dependent and even cultural-loaded thoughts are unable to be interpreted by code model. On the other hand, since language is a code system, inferential model can only interpret the process of communication partially.

\section{RELEVANCE THEORY}

\section{A. The Concept of Relevance}

Trying to solve the problems of the above models, Sperber and Wilson (1995) proposed the Relevance Theory. Relevance Theory agrees with Grice in that language communication isn't an encoding and decoding process alone, but more importantly, a conduct of getting inferences with context. Yet, Sperber and Wilson further state that a communicator, by requiring the listener's attention, indicates the thing he says is relevant to the hearer's interest, as is expressed in the following general principle:

Cognitive principle of relevance

Human cognition tends to be geared to the maximization of relevance. (Sperber and Wilson,1995, p.260)

Relevance is seen as a key of inputs to cognitive processes: utterances, thoughts, memories, actions, sounds, sights, smell, and so on, and context is crucial.

\section{B. Measurement of Relevance}

Sperber and Wilson (1995) holds, "An assumption is relevant in a context if and only if it has some contextual effect 
in that context." (p122) Yet relevance has degrees. Some assumptions are less relevant than others. The scale of relevance of the input is measured by the effect of the input and the effort that is needed to get the effect. Thus, relevance is measured by contextual effect and processing effort: When an utterance is understood with less effort, then it should be more relevant; when the effect of the listener's understanding is greater, then the utterance is more relevant.

Contextual effects are resulted when new information interacts with a context made of old information. The processing effort required depends on the effort that the listener consumed to form a proper context to understand the utterance in the listener's mind. The listener should try his best to get an understanding that satisfies his expectation of optimal relevance, and communication follows the general principle below:

Communicative principle of relevance

Every act of ostensive communication communicates a presumption of its own optimal relevance. (Sperber and Wilson, 1995, p.260)

An utterance gets its optimal relevance when it is relevant enough to be worth working on it, and moreover, when it is the most relevant utterance that the speaker is willing and able to produce. That is the explanation of Optimal Relevance. A speaker expects optimal relevance when he talks to others. The listener should try all his best to get an interpretation that satisfies this expectation of optimal relevance.

\section{Ostensive-inferential Model of Communication}

In order to put forward a full framework of communication and show the nature of communication, Sperber and Wilson (1995) provided the concept of Ostensive-Inferential Communication. In communication, the task of the speaker is to produce a stimulus, either verbal or non-verbal, which makes his informative intention mutually manifest. So for the speaker, communication is an act of letting the listener know his intention to express something, which is called ostension. It is the behavior "to make manifest an intention to make something manifest."(p227) As is mentioned, inference is related to the listener, and is the process of seeking relevance between the utterances and contextual assumptions, so the listener's task is to infer the intention from the evidences presented by the speaker. In this way, the dominant point of communication is Ostensive-Inferential. Communication involves the publication (ostension) and the recognition (inference) of intentions. The speaker's intention would be known by the audience because they have common cognitive environment, which is a set of facts that are clear enough to an individual. (From Prof.He Zhaoxiong's handouts for the 2006 summer course)

\section{Dynamic Context}

One of the central claims of relevance theory is that contexts are not fixed independently of the comprehension process; they are retrieved on constructed assumptions during the interpretation process. Traditionally, context is understood both linguistically and extra-linguistically. The interpretation in the communicative process is based on the shared knowledge of the participants. And this context pre-exists in the communicators' minds, and is fixed. However, in relevance theory, the notion of context of an utterance is "a psychological construct, a subset of the hearer's assumptions about the world; more especially it is the set of premises used in interpreting that utterance" (Sperber and Wilson,1995, p.15). Under this definition, context does not only refer to people's assumptions about the world or cognitive environment, but also includes any phenomenon that can enter the mind of the communicators. This notion of context also includes the text surrounding an utterance, which has sometimes been called co-text. To interpret the meaning of un utterance, communicators need to form a context accordingly with information he selected. The selection is what he needs to do because he must exclude some information to ensure the least consumption of the processing effort. In this way, the size of context is not fixed. The context is not fixed either, but selected, constructed and needs to be supplemented and extended in some cases. The only thing given is relevance. A communicators usually first assumes the utterance he is processing is relevant or he will not take the trouble to process it. After that, he tries to form a context where the interpretation could be achieved. An important characteristic of context in relevance theory is that it is assumed to be organized, and that this organization affects the accessibility of a particular piece of contextual information on a particular occasion. If the hearer wants to understand the communicative meaning, he needs to select, or indeed actively forms the context that seems to be helpful for him to achieve his purpose with the least effort.

The context for interpreting an utterance is not known by the participants in advance. It is a subset of all the assumptions that forms the cognitive environment of the communicators. Sperber and Wilson (1995)hold, when the communicators start to process certain new items of information, in their minds, they form a context initially making up of the assumptions, some of which are left over in their memories; some of which are resulted from the deduction they have made during the whole processing experience. After this, they may find this context is not enough and must be enlarged in order to meet the requirement to interpret the information. Sperber and Wilson suggest three ways to enlarge the context:

(1) Put in the context more assumptions which are got from the on-going logical deduction process;

(2) Put in the context more assumptions that had already been in their memories (most of them should be the encyclopedic generalizations and facts);

(3) Put in the context more assumptions about the observable environment.

The encyclopedic entry plays a crucial role in accessing contextual assumptions for use during comprehension. The encyclopedic entries for a concept consist of an organized set of propositions, each composed of further concepts. 


\section{UNDERSTANDING ADVERTISING IN THE FRAME OF RELEVANCE THEORY}

\section{A. Advertising as Communication}

A French advertising reviewer has ever said that the air we breathe every day actually is composed of oxygen, helium and advertisements. The famous American Marketing Association (AMA) says advertising is a special type of communication from a producer or company to the public. It is a communication to potential purchasers who pay attention to the information provided, who are persuaded to purchase or to experience things.

As a form of communication, advertising has its specific features. Advertising is a combination of verbal and non-verbal communication. Language is the most significant vehicle of communication, most advertisements employ language to transmit information. However, under certain circumstances, pictures, music and motions may be more expressive than language itself. In reality, most of the advertisements make use of language and non-language elements simultaneously in order to explicitly transmit the intended information. Advertising is a public communication rather than private one. It is a non-face-to-face and one-way communication. Advertisers must attract as large potential audience as possible, and the advertising communication is an audience-centered process.

How can an advertiser grasp audience's attention as much as possible? Once he attracts the audience's attention, how can he direct it to the understanding of his intention and make a lasting impression on the audience? And how can he make a full use of the medium and language to bring the desired return? In easier words, how can the advertising process be an effective communication?

Relevance theory emphasizes the interaction between cognitive psychology, mental deductive functions and grammatical processes, and between the effort the audience invests and the yield of information attained, so it provides an ideal tool for analyzing the process of the advertising communication. Advertising is a specific form of communication. The two main functions of advertising are informing and persuading/influencing. The former is subordinated to the latter. An ad designer gives an advertisement, of course, not for the purpose of making his audience know more about the world, but to sell a product or service.

In relevance theory terms, communication is successful only when (a) it attracts the attention of the target audience, (b) it indicates that the speaker wishes to convey a message of interest to the hearer, (c) the audience recognizes the speaker's informative intention and finds it worthwhile to make the effort to understand what the speaker intends to tell them, and (d) the message received by the hearer is as close as possible to what the speaker has in mind. A successful process of advertising communication meets all these requirements. All the advertising strategies that an advertiser takes are aimed at attracting the audience's attention and making him realize he needs the product that is promoted, and finally decide to use it. And if the product does sell well, it shows the advertisement is a success.

According to Relevance Theory, it is thoughts that are communicated. Thoughts mean mental representations, which the hearer is capable of understanding and believing. In other words, thoughts take the form of sets of assumptions. The ultimate goal of communication is to alter the hearer's thoughts, and that is why an advertiser engages in communication at all.

\section{B. Advertising-An Ostensive-inferential Communication}

Advertising communication is highly intentional. Usually, a communicator would offer clear ostension for the information he wants to communicate, and that is his informative intention. The reason why an advertiser is likely to use novel words and attractive linguistic features is the ostensive characteristics of advertising communication. The advertiser provides evidence and direct audience to infer his attention. On the other hand, the audience reading or watching a (TV) advertisement are busy searching for relevance. Both sides communicating are trying to adjust and enlarge the mutual cognitive environment in order to form an effective context.

The purpose of an advertisement is just to create a necessity of purchase. It is based on a simple reason for any purchase would take place: that is people's demand. The essential role of the advertisement is to attract the people's attention, and then try to find the optimal relevance through the inferring process. A successful communication will lead to the effective persuasion of the promoted products and as a result spread the popularity of the products. Finally an excellent advertisement realizes its most expected role ----to bring great profit for the businessman. On the contrary, if an ad fails to show the advertiser's intention or makes the audience be fed up with it, then it is doomed to gain a negative consequence. It is not just a failure of the single advertisement itself. The bad effect will spread to the whole field of products or service that the ad is promoting. The audience would simply not accept or dislikes the product, and then also would refuse the service or anything connected to the product as well as the company that produce the product or offer the service. The economical loss is unimaginable and immeasurable; Advertisers also create structure of meaning. Most contemporary ads do not directly ask the audience to buy products. Ads often seem more concerned with amusing us----setting a puzzle for us to work out, or demonstrating their own sophistication. The aim of doing this is to engage the audience in their structure of meaning to encourage them to participate by deciphering the advertiser's linguistic and visual signs and to enjoy this interpreting activity. In this process, the advertisers should offer the intended ideas in an ostensive way to ensure that what he intends to communicate will be adequately relevant to the audience in order to fulfill their real task-- manage to boost the sales of the products. The ostensive behavior in advertising is designed to catch the people's attention and make their attention focus on the advertiser's meaning, because human beings naturally focus on the most relevant things, which is a general cognitive law. So an act of ostension in 
advertising communication actually is a call for attention. Since processing information requires effort, the request to undertake the task has to be accompanied by reward. By requesting the audience's attention, the advertiser indicates that he is providing some relevant information which will make the audience's effort worthwhile.

\section{Case Study}

(1) The world is full of good-looking women.

But some really stop you.

They've got a certain glow that seems to come from within.

But then again...

Brush/Blush by Maybelline, stays true, stays fresh all day.

Now in 12 beliebable shades.

Maybe she's born with it.

Maybe it's Maybelline.

(---from Wu Keming, 1999)

This is an advertisement for Maybelline, one of the famous brands of cosmetics. At the beginning of the ad, the designer does not point out the product directly, but gives a statement _ "the world is full of good-looking women". Obviously the designers make use of the typical commercial rule, which can and must catch the attention of the audience. Beautiful women are certainly charming and attractive not only for men but also for women themselves. Men want to appreciate the good-looking women, while women on the other hand want to know whether they themselves are good-looking or not. Yet women want urgently to know how they can become good-looking. The designer deserves admiration for his cleverness shown in this ad. As Relevance Theory holds that each utterance starts to call the listener's attention, and thereafter expects relevance. This ad surely succeeds in this. As mentioned above, advertising is a communication between the ad designer and the public (as the readers or audience of advertisements). To achieve the success of communication, to make the public know the product being advertised, the ad designer (the communicator) produces utterances in such a way that the audience (or readers) will reach the intended interpretation, that is, what the designer takes into consideration. The designer also needs to guess what information is available to the audience (or readers) when they interpret an ad. The estimation of the audience's processing ability determines to what extent the utterances in the advertisements are made explicit or implicate. In this ad, the success lies in catching the attention of not only the women who are well-concerned the fashion but also the men who pay little even no attention to the cosmetic. That is to say, the ad fulfills the first aim -- to attract as large audience and potential audience as possible. Some audience really stopping to see it will keep this question in their mind:

a. What makes women so beautiful and charming?

With their own purposes, both men and women naturally continue the ad. The advertiser continues to give the audience the information that beauty comes from the interior, yet with "But then again..." the advertiser offers another ostensive stimulus. It arouses the curiosity of the audience, creates a new context and challenges the audience's processing effort to construct a new assumption:

b. if the beauty doesn't "come from within", where is it from?

Then the audience gains a new contextual effect, that is, Maybelline "stays true and stays fresh all day". They get the answer of the question - the beauty comes from Maybelline. During the interpretation process, new assumptions and contextual effects are achieved by the audience and the audience's extra processing efforts are awarded with more contextual effects. At the same time, the process of searching relevance retains the audience's attention for longer time and leaves them deeper impression on the advertised product, which is essential for a successful advertisement.

(2) I found the phone under my credit card.

It is an ad of Motorola cell phone. At the first sight of this sentence, it doesn't seem to be relevant at all. How can the reader interpret it and realize the intention of the advertiser? Since encoding and decoding is not the real essence of communication, instead, inference is, people cognize with the maximization of relevance. In this advertising communication, the reader's task is to make inference from the stimuli offered by the advertiser to find the optimal relevance, and finally finds the meaning conveyed. How can this advertisement be relevant to the product promoted? Having no enough assumptions to create a contextual environment at the first reading of this ad, the reader tries his best to search his memory combining encyclopedic and logic knowledge in order to find the relevant assumptions, and in doing so, a cognitive context is formed:

a) A credit card is a sort of paper card, which is small and thin, and usually kept in a wallet.

b) Anything that can be found under a credit card must be within the size of a card so that it could be covered by the card.

The context is furthered little by little with the process of the audience's inferring. How does the advertiser function in the ostension? The delicate utterance in the advertisement is the advertiser's contribution. _ the phone is found under the credit car. Normally, that is impossible. This works as a stimulus, and as a result, the audience's attention is called and it is sustained longer. He is given much freedom to imagine and associate, combines the old information in his mind with the context he constructs. The audience stimulated and directed by the above assumptions can process and complete the following assumption:

c) The phone that can be found under a credit card must be really small and thin. 
The act of ostension of the advertiser is to inform the audience the advantage of this brand of cell phone. Up to now, the advertiser's informative intention is fully grasped by the ad reader from the initial impression and cognition to the present degree of relevance. For an advertisement, the most important point is to persuade the consumer to act. With the processing effort paid, the reader of the ad achieves such a contextual effect:

d) The phone of Motorola is light and thin, and is very convenient and popular.

That effect is just the expectation of the advertiser, who has fulfilled his communicative intention. It is the inference that connects the semantic representations of an utterance and the message that the utterance eventually communicates.

\section{CONCLUSION}

The essence of RT is every act of ostensive communication communicates the presumption of its own optional relevance. (Sperber and Wilson, 1995)

In advertising communication, the public's attention is drawn to the products or services advocated by ad professionals, in this process, they need to get to know the messages that the advertisers try to convey. As the other side of communicators, ads professionals have interwoven their intended meaning into an ad item. However, what they want to show and want to express to the public must be made clear enough for the public to find the relevance. In this way, the public is required to infer/understand the message according to the on-going situation. Therefore, typically, advertising is a communication of ostension-inference, in which the audience needs to construct a dynamic context including the whole set of assumptions forming the cognitive environment of the communicators. In this way, RT is proved to be a good way to interpret any process of communication, including advertising in which the communicators are the advertising designer and the potential consumers.

\section{REFERENCES}

[1] Grice, G.N. (1975).Logic and conversation. New York: Academic Press.

[2] He, Zhaoxiong. (2010). A New Introduction to Pragmatics (2nd edn.). Shanghai: Shanghai Foreign Language Education Press.

[3] He, Ziran. (2000). Exploration of Pragmatics. Guangzhou: World Publishing Corporation.

[4] Levinson, S.C. (1983). Pragmatics. Cambridge: Cambridge University Press.

[5] Shannon, C and Weaver, W. (1962). The Mathematical Theory and Communication. Champaign-Urbana: University of Illinois Press.

[6] Sperber, D\& Wilson, D. (1995). Relevance: Communication and Cognition. Oxford: Basil Blackwell.

[7] Verschueren, J. (1999).Understanding Pragmatics. London: Arnold.

[8] Wu, Keming and Hu, Zhiwei. (1999). Catchy Jingles in English Advertisements. Beijing: Beijing University Press.

[9] Yule, G. (1996). Pragmatics. London: Oxford University Press.

[10] Prof. He Zhaoxiong's handouts for the 2006 summer course in Shanghai International Studies University.

Zhaohui Xu was born in ChangChun, Jilin Province, China, on August 15th, 1968, who has got a Master degree in foreign language and literature from JiLin University, Changchun, Jilin Province, China in 1992.

As a PROFESSOR, she teaches Linguistics, British and American Literature for the English major at School of Foreign Languages, ChangChun University of Science and Technology. In the recent 3 years, she has presided 3 research projects funded by the Education Department of Jilin Province, and by Office of Programs of Social Science, Jilin Province; she also had published 6 academic papers, among which "On Wittgenstein's Private Language Argument”, Social Science Front, (CSSCI, 2011. 1) was awarded a third prize for the research of social science by JiLin Province. At present she focuses her study on Pragmatics, Applied Linguistics, and Cognitive Linguistics.

Yanchun Zhou was born in Panshi, Jilin Province, China on March 15 th, 1978, who has got a degree of Master of Arts in foreign linguistics and applied linguistics from Changchun University of Science and Technology, Changchun, Jilin Province, China in 2003.

As an ASSOCIATE PROFESSOR, she teaches Foreign Linguistics of the English major at School of Foreign Languages, Changchun University of Science and Technology. Previous research interests are Linguistics and Semantics. At present she focuses on Pragmatics \& Cognitive Linguistics. 